\title{
TGF- $\beta 1$ and Its Signal Transduction Pathways: Are They Corelated With The Elastic Characteristics of Breast Lesions?
}

\author{
Meng Ke Zhang \\ Chinese PLA General Hospital \\ Shi Yu Li \\ Chinese PLA General Hospital \\ Bo Wang \\ Chinese PLA General Hospital \\ Gang Liu \\ Chinese PLA General Hospital \\ Zhi Li Wang ( $\sim$ wzllg@sina.com) \\ Chinese PLA General Hospital
}

\section{Research Article}

Keywords: TGF- $\beta 1$, Breast lesions, Correlation, Elastic characteristics, Signal transduction pathway

Posted Date: February 23rd, 2021

DOI: https://doi.org/10.21203/rs.3.rs-208458/v1

License: (c) (i) This work is licensed under a Creative Commons Attribution 4.0 International License. Read Full License 


\section{Abstract}

Background: Shear wave elastography (SWE) can evaluate the tissue stiffness. Previous studies showed that the elastic characteristics of breast lesions were related to the components of extracellular matrix (ECM) which was directly or indirectly regulated by transforming growth factor beta 1 (TGF- $\beta 1$ ). However, it is rarely reported whether there is a correlation between TGF- $\beta 1$ and the elastic characteristics of breast lesions. The purpose of this study was to investigate the relationship between TGF- $\beta 1$ with its signal transduction pathways and the elastic characteristics of breast lesions.

Methods: 135 breast lesions in 130 patients were included. Before operation or biopsy, SWE was performed. Elastic characteristics such as the maximum, mean, minimum and standard deviation (SD) of elastic modulus (Emax, Emean, Emin, Esd), the elastic ratio of the lesions to the peripheral tissue (Eratio) and the "stiff rim sign" were recorded. The expression levels of TGF- $\beta 1$, Smad2/3, Erk1/2, p38 MAPK, JNK2, PI3K and AKT were detected by immunohistochemistry. The elastic characteristics and the expression levels of the above-mentioned indexes of benign lesions were were analyzed.

Results: Emax, Emean, Esd, Eratio, "stiff rim sign" detection rate and the expression levels of TGF- $\beta$ 1, et al. of benign were lower than those of malignant lesions (Pख0.0001). The expression levels of TGF- $\beta$ 1, Smad2/3, Erk1/2, p38 MAPK, JNK2, PI3K and AKT were correlated with Emax, Emean, Esd, Eratio of breast lesions, the expression levels of TGF- $\beta$ 1, et al. of lesions with "stiff rim sign" were higher than those of lesions without "stiff rim sign" (Pख0.05). And the expression levels of Smad2/3, Erk1/2, p38 MAPK, JNK2, PI3K and AKT were corelated with that of TGF- $\beta 1$ ( $r=0.678,0.633,0.645,0.611,0.589,0.663$, $P \otimes 0.0001)$.

Conclusions: The expression levels of TGF- $\beta 1$, et al. of breast lesions were corelated with the elastic characteristics, the expression levels of Smad2/3, Erk1/2, p38 MAPK, JNK2, PI3K and AKT were corelated with that of TGF- $\beta 1$, which speculated that TGF- $\beta 1$ might play an important role in the stiffness regulation of breast lesions through multiple signal transduction pathways.

\section{Introduction}

Breast cancer is the most common malignant epithelial tumor in women with the highest fatality rate in female cancerous lesions[1]. With the rapid development of economy and society, China has become one of the countries with the fastest increasing incidence of breast cancer in the world[2]. Therefore, the situation of breast cancer in China is grim, which seriously endangers the physical and mental health of women. Studies have shown that early detection and early diagnosis of breast cancer have more significant therapeutic and prognostic effects[3, 4]. Therefore, how to early detect and diagnose breast cancer early has become a problem that long been expected to be solved by multiple examination methods.

At present, mammography is widely used as the main tool and ultrasound as the supplemental tool for screening breast lesions. However, mammography is limited by dense breast tissue, resulting in reduced sensitivity[5]. Previous studies have shown that increased breast density is an independent risk factor for breast cancer[6]. Ultrasound, which can overcome the limitation of breast density, has gradually begun to be recognized, and its application is becoming more and more widespread. Shear wave elastography (SWE) is a new ultrasound technology based on conventional ultrasound, which quantifies the tissue stiffness information with specific numerical values[7]. And its value in differential diagnosis of benign and malignant breast lesions has been proved by many studies[7-9].

Previous studies shown that the elastic characteristics of breast lesions were related to the components of extracellular matrix (ECM), and collagen and elastin in ECM were important factors that determine the elasticity of breast lesions[10,11]. While the changes of composition and structure of ECM are mainly regulated by transforming growth factor $\beta$ (TGF- $\beta$ ) $[12,13]$.

TGF- $\beta$ is widely distributed in human body, and TGF- $\beta 1$ is the most abundant. It can regulate the processes of cell carcinogenesis, proliferation, differentiation, apoptosis, metabolism and growth through TGF- $\beta 1 /$ Smad, TGF- $\beta 1 /$ MAPK, PI3K/AKT and other signal transduction pathways, and participate in almost the whole process of occurrence, development, invasion and metastasis of breast lesions[14-16]. In addition, TGF- $\beta 1$ can directly or indirectly promote the excessive deposition of collagen and fibrin in ECM, and inhibit the degradation of ECM, resulting in the increase of ECM stiffness[1719]. Therefore, TGF- $\beta 1$, ECM and elastic characteristics of breast lesions are closely related.

However, it is rarely reported whether there is a correlation between TGF- $\beta 1$ and the elastic characteristics of breast lesions, and it is urgent to explore whether the indexes of TGF- $\beta 1$ signal transduction pathway are related to the elastic characteristics of breast lesions. Therefore, the purpose of this study was to investigate the relationship between TGF- $\beta 1$ with its signal transduction pathways and the elastic characteristics of breast lesions.

\section{Materials And Methods}

\section{Patients}

The study was conducted in accordance with the Declaration of Helsinki (as revised in 2013). The study was approved by Medical ethics committee of our hospital (No. S2020-336-01), and written informed consent was obtained from all patients.

135 breast lesions in 130 patients who underwent surgical excision, ultrasound-guided vacuum-assisted biopsy (VAB) or core needle biopsy (CNB) after SWE examinations were included in the study from March 2018 to October 2018. The age of the patients ranged from 18 to 73 years old, with an average of (44 \pm 12 ) years, and the maximum diameter of the lesion ranged from 0.5 to $13.9 \mathrm{~cm}$, with an average of $(2.1 \pm 1.5) \mathrm{cm}$. The pathological result confirmed by VAB or surgery was considered as "gold standard". Then the axillary lymph node metastasis of patients with malignant breast lesions was followed up. 
A number of criteria were considered when including patients: I. Pathological results obtained by VAB or surgical excision; II. Clear and definite pathological diagnosis; III. Lesions haven't undergone neoadjuvant chemotherapy or radiotherapy; IV. No serious diseases of heart, lung, liver, kidney, etc. or malignant lesions; V. Patients can tolerate biopsy or surgical excision procedure; VI. Comprehensive information of clinical, ultrasound, pathology prognosis and follow-up; VII. Written informed consent was obtained.

\section{SWE examination}

Aixplorer ultrasound system (SuperSonic Imagine, Aix en Provence, France) with a L15-4 linear array probe was used for SWE examination. Ultrasound examination was performed at the site of the lesion firstly, and the best section to show the lesion was selected, and then switched to the SWE mode. Keep the patient to breathe smoothly, and the probe was placed at the site of the lesion with no pressure for 3 seconds to stabilize the image, then froze and store it. And after that the region of interest (ROI) was chosen. When choosing ROI, try to keep ROI to cover all parts of the lesion, especially the stiffest part. Then the maximum elastic modulus (Emax), mean elastic modulus (Emean), minimum elastic modulus (Emin), the standard deviation of elastic modulus (Esd) was recorded, and the elasticity ratio (Eratio) of the lesion shown by ROI to the peripheral normal breast tissue at the same depth was also recorded. Repeat the above steps in five different sections of the lesion. Calculate and record the mean value of Emax, Emean, Emin, Esd and Eratio in these five sets of data. Besides, the appearance of the red area of increased stiffness with or without open or closed ring at the edge of the lesion ("stiff rim sign") was observed.

\section{Immunohistochemistry}

The samples were fixed in formalin and embedded in paraffin, and then cut into sections with a thickness of $4 \mu \mathrm{m}$, and then TGF- $\beta 1$, Smad2/3, Erk1/2, p38 MAPK, JNK2, PI3K and AKT expression was evaluated by immunohistochemistry. Image-Pro Plus 6.0 was used for semi-quantitative analysis of immunohistochemical results. Five ROls were randomly selected from each sample under the 400x field of view and photographed to measure the integrated optical density (IOD) and area. The yellow area is the positive expression area. Expression levels of TGF- $\beta 1$ and other factors were expressed by average optical density (IOD/area).

\section{Statistical analysis}

SPSS 26.0, standard version (SPSS Inc., Chicago, IL, USA) statistical software was used for statistical analysis. The quantitative data were expressed as $(\mathrm{x} \pm \mathrm{s})$ and the qualitative data were expressed as \%. Student's t test was used to compare the differences between groups of quantitative data, and $\mathrm{c}^{2}$ test was used to compare the differences of qualitative data. Taking the pathological results as the "gold standard", the receiver operator characteristic curve (ROC) of each factor were drawn respectively, and the efficacy was evaluated by the area under the curve (AUC), and the cutoff value, sensitivity and specificity were analyzed, and the differences among AUC were compared by Z test. Spearman rank correlation test was used for correlation analysis. $P \square$ 0.05 was considered as the difference was statistically significant.

\section{Results}

\section{Pathological results}

Of the 135 breast lesions, 84 (62.2\%, 84/135) were benign, including 32 fibroadenomas, 40 adenosis, 3 intraductal papillomas, 8 inflammatory lesions, 1 benign phyllodes tumor, and 51 (37.8\%, 51/135) were malignant, among them, there were 46 invasive carcinomas, 3 intraductal carcinomas and 2 mucinous carcinomas.

\section{Analysis of elastic characteristics of breast lesions}

The elastic characteristics of benign and malignant breast lesions were seen in Table 1, Figure 1A and Figure 2A. The Emax, Emean, Esd and Eratio of benign breast lesions was significantly lower than those of malignant lesions $(P<0.001)$, but there was no significant difference in Emin between benign and malignant breast lesions ( $\mathrm{P} \otimes 0.202)$. Besides, the detection rate of "stiff rim sign" in malignant lesions was significantly higher than that of benign lesions $(P<0.001)$.

\section{Expression levels of TGF- $\beta 1$ and other factors in breast lesions}

The expression levels of TGF- $\beta 1$ and other factors in breast lesions were seen in Table 2, Figure 1B H and Figure 2B H. Immunohistochemical staining showed that TGF- $\beta 1$ and PI3K were mainly expressed in the cytoplasm, while Smad2/3, Erk1/2, p38 MAPK, JNK2 and AKT were mainly expressed in the cytoplasm and nucleus. And the expression levels of TGF- $\beta 1$ and other factors in malignant breast lesions were significantly higher than those in benign lesions $(P<0.001)$.

When using the expression levels of TGF- $\beta 1$ and other factors as an index respectively for the differential diagnosis of benign and malignant breast lesions, the ROC curve was shown in Figure 3, the AUC were 0.931 (0.874-0.967), 0.953 (0.901-0.982), 0.920 (0.861-0.960), 0.957 (0.902-0.986), 0.934 (0.874-0.971), $0.960(0.901-0.989)$ and 0.939 (0.883-0.974), respectively. $Z$ test showed that there was no significant difference among the seven groups $(P$ $>0.05$ ). When the cutoff value of the average optical density of TGF- $\beta 1$, Smad2/3, Erk1/2, p38 MAPK, JNK2, PI3K and AKT was > 0.2175, > 0.1496, > $0.2036,>0.1447,>0.1583,>0.2624,>0.1230$ respectively, the sensitivity and specificity for differential diagnosis of benign and malignant breast lesions were $90.0 \%$ and $88.2 \%, 93.9 \%$ and $90.2 \%, 80.0 \%$ and $89.4 \%, 89.1 \%$ and $95.5 \%, 90.2 \%$ and $85.0 \%, 93.6 \%$ and $94.4 \%, 80.0 \%$ and $89.4 \%$, respectively. 


\section{Correlation analysis}

The correlation between the expression levels of TGF- $\beta 1$ and other factors and elastic characteristics in breast lesions was shown in Figure 4 7. Spearman test showed that the expression levels of TGF- $\beta 1$ and other factors were positively correlated with Emax, Emean, Esd and Eratio in breast lesions

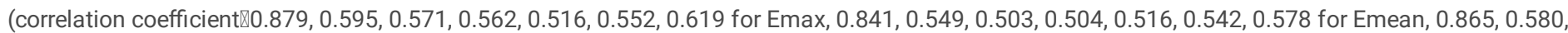
$0.566,0.593,0.514,0.559,0.649$ for Esd and $0.746,0.510,0.507,0.506,0.536,0.511,0.550$ for Eratio, $P \otimes 0.0001)$.

Expression levels of TGF- $\beta 1$ and other factors in breast lesions with and without "stiff rim sign" could be seen in Table 3. Immunohistochemical staining showed that the expression levels of TGF- $\beta 1$ and other factors in breast lesions with "stiff rim sign" were significantly higher than those in breast lesions without "stiff rim sign" (Pख0.001).

The correlation between the expression levels of TGF- $\beta 1$ and other factors in breast lesions was shown in Figure 8. Spearman test showed that the expression levels of Smad2/3, Erk1/2, p38 MAPK, JNK2, PI3K and AKT were positively correlated with TGF- $\beta 1$ in breast lesions (correlation coefficient $\bigotimes$ $0.678,0.633,0.645,0.611,0.589,0.663, P \otimes 0.0001)$.

\section{Axillary lymph node metastasis}

Expression levels of TGF- $\beta 1$ and other factors in malignant breast lesions with and without axillary lymph node metastasis could be seen in Table 4 . The difference between malignant breast lesions with axillary lymph node metastasis and malignant breast lesions without axillary lymph node metastasis lied in that the expression levels of TGF- $\beta 1$ and other factors of former were significantly higher than those of the latter $(P<0.05)$.

Basing on the expression levels of TGF- $\beta 1$ and other factors in malignant breast lesions, ROC curves of which for differential diagnosis of malignant breast lesions with and without axillary lymph node metastasis were shown in Figure 9. The AUC were 0.853 (0.703-0.946), 0.697 (0.529-0.834), 0.694 (0.527-0.832), 0.706 (0.531-0.845), 0.654 (0.466-0.813), 0.667 (0.493-0.813) and 0.689 (0.516-0.831), respectively. When the expression levels of TGF- $\beta 1$, Smad2/3, Erk1/2, p38 MAPK, JNK2, PI3K and AKT were cut off by average optical density >0.3138, >0.2679, >0.2457, >0.2812, >0.2760, $>0.3075,>$ 0.2348 respectively, the sensitivity and specificity for differential diagnosis of malignant breast lesions with or without axillary lymph node metastasis were $86.7 \%$ and $83.3 \%, 80.0 \%$ and $62.5 \%, 80.0 \%$ and $58.3 \%, 69.2 \%$ and $65.2 \%, 50.0 \%$ and $80.0 \%, 86.7 \%$ and $40.9 \%, 42.9 \%$ and $91.3 \%$, respectively.

\section{Quantile regression analysis}

As shown in Table 5 8, the percentile regression analysis was performed with the expression levels of TGF- $\beta$ 1, Smad2/3, Erk1/2, p38 MAPK, JNK2, PI3K and AKT in breast lesions as independent variables and Emax, Emean, Esd and Eratio as target variables respectively. At different quantiles, only the expression level of TGF- $\beta 1$ always had a significant positive effect on Emax, Emean, Esd and Eratio, while Smad2/3 only had a certain effect on Emean at the point of 0.75 th quartile, a negative effect on Eratio at the point of 0.45 th quartile. Erk $1 / 2$ only had a certain effect on Emean at the 0.75 th quartile. That is, the expression level of TGF- $\beta 1$ is the most important factor to determine the Emax, Emean, Esd and Eratio of breast lesions.

\section{Logistic regression analysis}

Taking the expression levels of TGF- $\beta 1$, Smad2/3, Erk1/2, p38MAPK, JNK2, PI3K and AKT in breast lesions as independent variables and "stiff rim sign" as dependent variable, logistic regression analysis was performed. The logistic regression equation was established as follows:

Logit $(P)=-5.977 \bigotimes 17.049 X_{1}$

$\mathrm{X}_{1}$ represented the expression level of TGF- $\beta 1$, that is, the expression level of TGF- $\beta 1$ was the main factor determining the presence or absence of "stiff rim sign", as shown in Table 9.

\section{Discussion}

SWE could quantitatively evaluate the elastic characteristics of breast lesions and more accurately judge the benign and malignant breast lesions. Our study showed that there were significant differences in elastic characteristics between benign and malignant breast lesions, which were the same as those of previous studies[8,20]. For malignant breast lesions, a large number of cancer cells proliferated, invaded and infiltrated the normal breast stroma and adipose tissue, and interacted with the tumor microenvironment, causing complex connective tissue hyperplasia and fibrosis, which were important typical pathological changes in the process of tumor development and invasion, they could lead to overexpression and accumulation of ECM components, rearrangement and cross-linking of ECM structure[21, 22], and increase the stiffness of the lesions. At the same time, the proliferation and fibrosis of connective tissue caused by the continuous invasion of cancer cells made the fibroblasts grow to the edge of the lesion[23], according to the number of collagen and elastic fibers and the degree of fibrosis, the lesions exerted different degrees of tension on the surrounding tissue[24], and elastin and fibrin would harden under stretching[25], thus increasing the stiffness of the tissue around the lesion by 2-10 times. As a result, the "stiff rim sign" appeared.

Our study found that the expression levels of TGF- $\beta 1$ and other factors in malignant breast lesions were significantly higher than those in benign breast lesions. It was not difficult to understand such results. TGF- $\beta$ had both inhibitory and promoting effects on tumor cells[26]. In the early stage of tumorigenesis, TGF- $\beta$ could induce tumor cell apoptosis and inhibit tumor growth through the TGF- $\beta$ /Smad signal pathway, but with the occurrence and development of tumor, most cancer cells could secrete TGF- $\beta$, and the elevated level of TGF- $\beta$ could promote the occurrence and development of tumor[27]. The proliferation and invasion of cancer cells led to the activation of TGF- $\beta 1$ and the increase of TGF- $\beta 1$ expression, which affected the growth of cancer 
cells and promoted the transformation of normal fibroblasts into cancer associated fibroblasts (CAFs)[28, 29]. CAFs could interact with cancer ECM to promote the growth, development, invasion and metastasis of cancer, thus further increasing the expression level of TGF- $\beta 1$. For TGF- $\beta 1$ could participate in almost the whole process of occurrence, development, invasion and metastasis of breast lesions through TGF- $\beta 1 / \mathrm{Smad}$, TGF- $\beta 1 / \mathrm{MAPK}$, PI3K/AKT and other signal transduction pathways, the expression levels of TGF- $\beta 1$ and other factors in malignant breast lesions were naturally higher than those in benign lesions. These also explained another result of this study: the expression levels of TGF- $\beta 1$ and other factors in malignant breast lesions with or without axillary lymph node metastasis were significantly different.

The study also showed that the expression levels of TGF- $\beta 1$ and other factors in breast lesions had a certain value in the differential diagnosis of benign and malignant breast lesions, suggesting that TGF- $\beta 1$ and other factors might be used as new indexes for differential diagnosis of benign and malignant breast lesions and new breakthrough points for clinical diagnosis and treatment.

In our study, the expression level of TGF- $\beta 1$ was found to be correlated with Emax, Emean, Esd, Eratio, and the expression level of TGF- $\beta 1$ in breast lesions with "stiff rim sign" was significantly higher than those in breast lesions without "stiff rim sign". According to the previous studies, on the one hand, TGF- $\beta 1$ could promote the activation and production of CAFs. CAFs mainly synthesizes and secretes ECM proteins and proteins related to ECM remodeling, which in turn promotes the excessive accumulation of ECM components and the remodeling of ECM structure[18, 29, 30]. On the other hand, TGF- $\beta 1$ could directly stimulate the synthesis and cross-linking rearrangement of collagen, elastin and laminin, and inhibit the activity of enzymes that degrade ECM components to inhibit their degradation, lead to excessive accumulation of ECM components and structural changes of ECM, and increased ECM stiffness[22, 31]. In addition, TGF- $\beta 1$ could also improve cell adhesion by promoting cancer cell synthesis and secretion of a variety of proteases, resulting in cancer cells adhering to the surrounding breast stroma and adipose tissue, resulting in reduced lesion activity and increased lesion stiffness[32].

In the process of carcinogenesis and development, the signal transmitted by TGF- $\beta 1$ could be transmitted to the nucleus through TGF- $\beta 1 / S m a d$ signal pathway, on one hand, it could directly up-regulate the expression of collagen fibers[33], and on the other hand, it could induce the process of epithelialmesenchymal transformation (EMT). EMT could upregulate the expression of ECM components such as collagen and fibronectin[16], and thus increase the stiffness of ECM. Cancer cells could produce oxidative stress in the process of differentiation and invasion, and reactive oxygen species could promote the initiation of TGF- $\beta 1 /$ Smad signal transduction pathway, hinder the degradation of fibrin, make fibrin deposition[34], and lead to the stiffening of ECM. Similarly, the increased expression of TGF- $\beta 1$ could also induce the occurrence of EMT process by activating MAPK signal transduction pathway and $\mathrm{PI3K} / \mathrm{AKT} / \mathrm{mTOR}$ signal transduction pathway[16], which increased the stiffness of ECM and leads to the stiffening of lesions. And with the increase of ECM stiffness, the signal transduction of PI3K/AKT pathway can be activated and enhanced[35]. Therefore, it is not difficult to understand the correlation between the expression levels of Smad2/3, Erk1/2, p38 MAPK, JNK2, PI3K, AKT and Emax, Emean, Esd, Eratio, "stiff rim sign" in this study.

The study also found that the expression levels of Smad2/3, Erk1/2, p38MAPK, JNK2, PI3K and AKT in breast lesions were correlated with that of TGF- $\beta 1$, which further suggested that TGF- $\beta 1$ might indeed participate in almost the whole process of occurrence, development, invasion and metastasis of breast lesions through signal transduction pathways such as TGF- $\beta 1 /$ Smad, TGF- $\beta 1 /$ MAPK, PI3K/AKT.

One of the important factors affecting the prognosis and 5-year survival time of patients with malignant breast lesions was whether the disease had lymph node metastasis, especially axillary lymph node metastasis[36]. Our study showed that the expression levels of TGF- $\beta 1$ and other factors in malignant breast lesions had a certain value in predicting whether malignant breast lesions had axillary lymph node metastasis or not, which suggested that the presence or absence of axillary lymph node metastasis in malignant breast lesions might be evaluated according to the expression levels of TGF- $\beta 1$ and other factors, it is of great significance for axillary lymph node dissection in the clinical operation of malignant breast lesions.

It was also found in the study that the expression level of TGF- $\beta 1$ was the main factor affecting the elastic characteristics of breast lesions, such as Emax, Emean, Esd, Eratio, and the expression level of TGF- $\beta 1$ was the independent risk factor for the presence of "stiff rim sign", which suggested that TGF- $\beta 1$ might play an important role in the regulation of elastic characteristics of breast lesions, or it might become a new breakthrough point for differential diagnosis of benign and malignant breast lesions and a potential target for treatment.

There are some limitations in this study. In this study, the main components of ECM such as collagen fibers and elastic fibers were not detected, so the relationships between collagen fibers, elastic fibers and the expression levels of TGF- $\beta 1$ and other factors and the elastic characteristics of breast lesions were not analyzed, so as to further explore whether TGF- $\beta 1$ regulates the stiffness of breast lesions by regulating ECM, and whether conventional ultrasound features were related to the expression levels of TGF- $\beta 1$ and other factors were not analyzed, either. Therefore, the next step is to carry out the above two aspects of research, in order to make the study more in-depth and comprehensive.

In conclusion, the expression levels of TGF- $\beta 1$ and other factors in breast lesions were correlated with Emax, Emean, Esd, Eratio, "stiff rim sign" and axillary lymph node metastasis, and the expression level of TGF- $\beta 1$ was the main factor affecting the Emax, Emean, Esd, Eratio, "stiff rim sign", the expression levels of Smad2/3, Erk1/2, p38 MAPK, JNK2, PI3K and AKT were also correlated with the expression level of TGF- $\beta 1$, which speculated that TGF- $\beta 1$ might play an important role in the stiffness regulation of breast lesions through multiple signal transduction pathways.

\section{Abbreviations}

SWE: Shear wave elastography

ECM: extracellular matrix 
TGF- $\beta$ : transforming growth factor $\beta$

VAB: vacuum-assisted biopsy

CNB: core needle biopsy

ROI: region of interest

IOD: integrated optical density

ROC: receiver operator characteristic curve

AUC: area under the curve

CAFs: cancer associated fibroblasts

EMT: epithelial-mesenchymal transformation

\section{Declarations}

\section{Ethics approval and consent to participate}

The authors are accountable for all aspects of the work in ensuring that questions related to the accuracy or integrity of any part of the work are appropriately investigated and resolved. The study was conducted in accordance with the Declaration of Helsinki (as revised in 2013). The study was approved by Medical ethics committee of China PLA General Hospital (No. S2020-336-01), and written informed consent was obtained from all patients.

\section{Consent for publication}

Not applicable

\section{Availability of data and materials}

The datasets used and/or analyzed during the current study are available from the corresponding author on reasonable request.

\section{Competing interests}

We declare that we have no financial and personal relationships with other people or organizations that can inappropriately influence our work, there is no professional or other personal interest of any nature or kind in any product, service and/or company that could be construed as influencing the position presented in, or the review of, the manuscript entitled.

\section{Funding}

This work was supported by the National Natural Science Foundation of China (81771832, 82071925); and the Military Top project of Youth Training for Medical Science and Technology (19QNP071).

\section{Authors' contributions}

Z.L.W. and G. L. designed the work;M.K.Z. and B. W. the acquisition, analysis;

1. Y. L and B. W. colleeted and interpretated data;

M.K.Z and S. Y. L prepared all figures;

M.K.Z. have drafted the work;

Z.L.W. and G. L. made critical revision of the manuscript for important intellectual content.

All authors reviewed the manuscript.

\section{Acknowledgements}

Not applicable

\section{References}

1. Siegel RL, Miller KD, Jemal A: Cancer statistics, 2019. CA Cancer J Clin 2019, 69(1):7-34.

2. Feng RM, Zong YN, Cao SM, Xu RH: Current cancer situation in China: good or bad news from the 2018 Global Cancer Statistics? Cancer Commun (Lond) 2019, 39(1):22. 
3. Duncan W, Kerr GR: The curability of breast cancer. Br Med J 1976, 2(6039):781-783.

4. Harbeck N, Gnant M: Breast cancer. Lancet 2017, 389(10074):1134-1150.

5. Geisel J, Raghu M, Hooley R: The Role of Ultrasound in Breast Cancer Screening: The Case for and Against Ultrasound. Semin Ultrasound CT MR 2018, 39(1):25-34.

6. Vachon CM, van Gils CH, Sellers TA, Ghosh K, Pruthi S, Brandt KR, Pankratz VS: Mammographic density, breast cancer risk and risk prediction. Breast Cancer Res 2007, 9(6):217.

7. Xue Y, Yao S, Li X, Zhang H: Value of shear wave elastography in discriminating malignant and benign breast lesions: A meta-analysis. Medicine 2017, 96(42):e7412.

8. Suvannarerg V, Chitchumnong P, Apiwat W, Lertdamrongdej L, Tretipwanit N, Pisarnturakit P, Sitthinamsuwan P, Thiravit S, Muangsomboon K, Korpraphong P: Diagnostic performance of qualitative and quantitative shear wave elastography in differentiating malignant from benign breast masses, and association with the histological prognostic factors. Quant Imaging Med Surg 2019, 9(3):386-398.

9. Hari S, Paul SB, Vidyasagar R, Dhamija E, Adarsh AD, Thulkar S, Mathur S, Sreenivas V, Sharma S, Srivastava A et al: Breast mass characterization using shear wave elastography and ultrasound. Diagn Interv Imaging 2018, 99(11):699-707.

10. Liu G, Zhang MK, He Y, Li XR, Wang ZL: Shear wave elasticity of breast lesions: would it be correlated with the extracellular matrix components? Gland Surg 2019, 8(4):399-406.

11. Wang ZL, Sun L, Li Y, Li N: Relationship between elasticity and collagen fiber content in breast disease: a preliminary report. Ultrasonics 2015, 57:4449.

12. Papageorgis $\mathrm{P}$, Stylianopoulos T: Role of TGFbeta in regulation of the tumor microenvironment and drug delivery (review). Int $\mathrm{J}$ Onco/2015, 46(3):933943.

13. Curran CS, Keely PJ: Breast tumor and stromal cell responses to TGF-beta and hypoxia in matrix deposition. Matrix Bio/2013, 32(2):95-105.

14. Tan RJ, Zhou D, Liu Y: Signaling Crosstalk between Tubular Epithelial Cells and Interstitial Fibroblasts after Kidney Injury. Kidney Dis (Basel) 2016, 2(3):136-144.

15. Cantelli G, Crosas-Molist E, Georgouli M, Sanz-Moreno V: TGFBeta-induced transcription in cancer. Semin Cancer Bio/ 2017, 42:60-69.

16. Katsuno Y, Lamouille S, Derynck R: TGF-beta signaling and epithelial-mesenchymal transition in cancer progression. Curr Opin Onco/ 2013, 25(1):7684.

17. Porras AM, Hutson HN, Berger AJ, Masters KS: Engineering approaches to study fibrosis in 3-D in vitro systems. Curr Opin Biotechno/ 2016, 40:24-30.

18. Arimura H, Shukunami C, Tokunaga T, Karasugi T, Okamoto N, Taniwaki T, Sakamoto H, Mizuta H, Hiraki Y: TGF-beta1 Improves Biomechanical Strength by Extracellular Matrix Accumulation Without Increasing the Number of Tenogenic Lineage Cells in a Rat Rotator Cuff Repair Model. Am J Sports Med 2017, 45(10):2394-2404.

19. Li X, Guo L, Yang X, Wang J, Hou Y, Zhu S, Du J, Feng J, Xie Y, Zhuang L et al: TGF-beta1-induced connexin43 promotes scar formation via the Erk/MMP-1/collagen III pathway. J Oral Rehabil 2019.

20. Liu G, Zhang MK, He Y, Liu Y, Li XR, Wang ZL: BI-RADS 4 breast lesions: could multi-mode ultrasound be helpful for their diagnosis? Gland Surg 2019, 8(3):258-270.

21. Kaushik N, Kim S, Suh Y, Lee SJ: Proinvasive extracellular matrix remodeling for tumor progression. Arch Pharm Res 2019, 42(1):40-47.

22. Jena MK, Janjanam J: Role of extracellular matrix in breast cancer development: a brief update. F1000Res 2018, 7:274.

23. Insana MF, Pellot-Barakat C, Sridhar M, Lindfors KK: Viscoelastic imaging of breast tumor microenvironment with ultrasound. $J$ Mammary Gland Biol Neoplasia 2004, 9(4):393-404.

24. Garra BS, Cespedes El, Ophir J, Spratt SR, Zuurbier RA, Magnant CM, Pennanen MF: Elastography of breast lesions: initial clinical results. Radiology 1997, 202(1):79-86.

25. Malandrino A, Mak M, Kamm RD, Moeendarbary E: Complex mechanics of the heterogeneous extracellular matrix in cancer. Extreme Mech Lett 2018, 21:25-34.

26. Chen W, Zhong X, Wei Y, Liu Y, Yi Q, Zhang G, He L, Chen F, Liu Y, Luo J: TGF-beta Regulates Survivin to Affect Cell Cycle and the Expression of EGFR and MMP9 in Glioblastoma. Mol Neurobiol 2016, 53(3):1648-1653.

27. Levy L, Hill CS: Alterations in components of the TGF-beta superfamily signaling pathways in human cancer. Cytokine Growth Factor Rev 2006, 17(12):41-58.

28. Ahmadi A, Najafi M, Farhood B, Mortezaee K: Transforming growth factor-beta signaling: Tumorigenesis and targeting for cancer therapy. $J$ Cell Physiol 2019, 234(8):12173-12187.

29. Brown NF, Marshall JF: Integrin-Mediated TGFbeta Activation Modulates the Tumour Microenvironment. Cancers (Basel) $2019,11(9): 1221$.

30. Erdogan B, Webb DJ: Cancer-associated fibroblasts modulate growth factor signaling and extracellular matrix remodeling to regulate tumor metastasis. Biochem Soc Trans 2017, 45(1):229-236.

31. Kawecki M, Labus W, Klama-Baryla A, Kitala D, Kraut M, Glik J, Misiuga M, Nowak M, Bielecki T, Kasperczyk A: A review of decellurization methods caused by an urgent need for quality control of cell-free extracellular matrix' scaffolds and their role in regenerative medicine. $J$ Biomed Mater Res $B$ Appl Biomater 2018, 106(2):909-923. 
32. Kim HJ, Park JH, Shin JM, Yang HW, Lee HM, Park IH: TGF-beta1-induced HSP47 regulates extracellular matrix accumulation via Smad2/3 signaling pathways in nasal fibroblasts. Sci Rep 2019, 9(1):15563.

33. Busnadiego O, Gonzalez-Santamaria J, Lagares D, Guinea-Viniegra J, Pichol-Thievend C, Muller L, Rodriguez-Pascual F: LOXL4 is induced by transforming growth factor beta1 through Smad and JunB/Fra2 and contributes to vascular matrix remodeling. Mol Cell Bio/ 2013, 33(12):2388-2401.

34. Samarakoon R, Dobberfuhl AD, Cooley C, Overstreet JM, Patel S, Goldschmeding R, Meldrum KK, Higgins PJ: Induction of renal fibrotic genes by TGFbeta1 requires EGFR activation, p53 and reactive oxygen species. Cell Signa/ 2013, 25(11):2198-2209.

35. Levental KR, Yu H, Kass L, Lakins JN, Egeblad M, Erler JT, Fong SF, Csiszar K, Giaccia A, Weninger W et al: Matrix crosslinking forces tumor progression by enhancing integrin signaling. Cell 2009, 139(5):891-906.

36. Berardi DE, Flumian C, Rodriguez CE, Bessone MI, Cirigliano SM, Joffe ED, Fiszman GL, Urtreger AJ, Todaro LB: PKCdelta Inhibition Impairs Mammary Cancer Proliferative Capacity But Selects Cancer Stem Cells, Involving Autophagy. J Cell Biochem 2016, 117(3):730-740.

\section{Tables}

Table 1 Comparison of elastic characteristics between benign and malignant breast lesions

\begin{tabular}{|c|c|c|c|c|}
\hline Factors & $\begin{array}{l}\text { Benign lesions } \\
(n=84)\end{array}$ & $\begin{array}{l}\text { Malignant lesions } \\
(n=51)\end{array}$ & $t\left(t^{\prime}\right) / x^{2}$ & $P$ \\
\hline $\operatorname{Emax}(\mathrm{kPa})$ * & $58.2 \pm 50.5$ & $161.9 \pm 79.5$ & 9.276 & $\bowtie 0.001$ \\
\hline Emean $(\mathrm{kPa})^{\star}$ & $35.9 \pm 26.4$ & $99.6 \pm 51.9$ & 9.433 & $\otimes 0.001$ \\
\hline $\operatorname{Emin}(\mathrm{kPa})$ & $15.4 \pm 12.9$ & $20.6 \pm 19.5$ & 1.287 & 0.202 \\
\hline Esd $(\mathrm{kPa})^{\star}$ & $8.9 \pm 7.9$ & $30.1 \pm 17.5$ & 9.011 & $\bowtie 0.001$ \\
\hline Eratio * & $2.1 \pm 1.7$ & $6.0 \pm 4.1$ & 7.625 & $\bowtie 0.001$ \\
\hline Stiff rim sign $[\boldsymbol{n}(\%)]^{\star}$ & $4(4.8)$ & $38(74.5)$ & 72.030 & $\otimes 0.001$ \\
\hline
\end{tabular}

*statistical significance.

Table 2 Comparison of expression levels of TGF- $\beta 1$ and other factors between benign and malignant breast lesions $(\mathrm{x} \pm \mathrm{s})$

\begin{tabular}{|c|c|c|c|c|}
\hline Factors & $\begin{array}{l}\text { Benign lesions } \\
(n=84)\end{array}$ & $\begin{array}{l}\text { Malignant lesions } \\
(n=51)\end{array}$ & $t\left(t^{\prime}\right)$ & $P$ \\
\hline TGF- $\beta 1$ * & $0.1038 \pm 0.0092$ & $0.2995 \pm 0.01114$ & 13.300 & $\varangle 0.001$ \\
\hline Smad2/3* & $0.0745 \pm 0.0497$ & $0.2511 \pm 0.0754$ & 16.160 & $\otimes 0.001$ \\
\hline Erk1/2 * & $0.1242 \pm 0.0552$ & $0.2547 \pm 0.0667$ & 12.300 & $\otimes 0.001$ \\
\hline p38 MAPK* & $0.0459 \pm 0.0516$ & $0.2613 \pm 0.0914$ & 15.930 & $\varangle 0.001$ \\
\hline JNK2* & $0.1101 \pm 0.0549$ & $0.2558 \pm 0.0720$ & 12.450 & $\llbracket 0.001$ \\
\hline $\mathrm{PI} 3 \mathrm{~K}$ * & $0.1240 \pm 0.0702$ & $0.3425 \pm 0.0608$ & 16.640 & $\varangle 0.001$ \\
\hline AKT * & $0.0741 \pm 0.0546$ & $0.2166 \pm 0.0679$ & 13.070 & $₫ 0.001$ \\
\hline
\end{tabular}

*statistical significance.

Table 3 Comparison of expression levels of TGF- $\beta 1$ and other factors in breast lesions with and without "stiff rim sign" ( $\mathrm{X} \pm \mathrm{s}$ )

\begin{tabular}{|c|c|c|c|c|}
\hline \multirow[t]{2}{*}{ Factors } & \multicolumn{2}{|l|}{ Stiff rim sign } & \multirow[t]{2}{*}{$t\left(t^{\prime}\right)$} & \multirow[t]{2}{*}{$P$} \\
\hline & $\operatorname{Yes}(n=42)$ & None $(n=93)$ & & \\
\hline TGF- $\beta 1^{*}$ & $0.3090 \pm 0.0682$ & $0.1164 \pm 0.0960$ & 11.720 & $\otimes 0.001$ \\
\hline Smad2/3* & $0.2332 \pm 0.0981$ & $0.1004 \pm 0.0792$ & 8.242 & $\bowtie 0.001$ \\
\hline Erk1/2* & $0.2441 \pm 0.0831$ & $0.1416 \pm 0.0683$ & 7.539 & $\otimes 0.001$ \\
\hline p38 MAPK* & $0.2429 \pm 0.1116$ & $0.0832 \pm 0.0998$ & 7.673 & $\bowtie 0.001$ \\
\hline JNK2* & $0.2429 \pm 0.0875$ & $0.1285 \pm 0.0729$ & 7.321 & $\bowtie 0.001$ \\
\hline $\mathrm{PI} 3 K^{*}$ & $0.3212 \pm 0.0954$ & $0.1692 \pm 0.1096$ & 7.130 & $\otimes 0.001$ \\
\hline $\mathrm{AKT}^{*}$ & $0.2025 \pm 0.0886$ & $0.0945 \pm 0.0712$ & 7.332 & $\nabla 0.001$ \\
\hline
\end{tabular}

Page $8 / 15$ 
*statistical significance.

Table 4 Comparison of expression levels of TGF- $\beta 1$ and other factors in malignant breast lesions with and without axillary lymph node metastasis ( $\pm \pm \mathbf{s}$ )

\begin{tabular}{|lllll|}
\hline Factors & Metastasis & & $\mathrm{t}\left(\mathrm{t}^{\prime}\right)$ & $P$ \\
\cline { 2 - 5 } & Yes $(n=15)$ & None $(n=36)$ & & \\
\hline TGF- $\beta 1 *$ & $0.3204 \pm 0.0381$ & $0.2648 \pm 0.0650$ & 2.999 & 0.0048 \\
\hline Smad2/3* & $0.2956 \pm 0.0251$ & $0.2513 \pm 0.0628$ & 2.592 & 0.0136 \\
\hline Erk1/2* & $0.2814 \pm 0.0609$ & $0.2414 \pm 0.0553$ & 2.118 & 0.0410 \\
\hline p38 MAPK* & $0.2999 \pm 0.0506$ & $0.2484 \pm 0.0759$ & 2.180 & 0.0363 \\
\hline JNK2* & $0.2832 \pm 0.0627$ & $0.2415 \pm 0.0507$ & 2.063 & 0.0478 \\
\hline PI3K * & $0.3396 \pm 0.0316$ & $0.3110 \pm 0.0459$ & 2.094 & 0.0436 \\
\hline AKT * & $0.2225 \pm 0.0716$ & $0.1704 \pm 0.0713$ & 2.154 & 0.0382 \\
\hline
\end{tabular}

*statistical significance.

Table 5 Percentile regression analysis results of Emax and the expression levels of TGF- $\beta$ 1, Smad2/3, Erk1/2, p38 MAPK, JNK2, PI3K and AKT

\begin{tabular}{|c|c|c|c|c|c|c|c|c|c|c|}
\hline \multirow[t]{2}{*}{ Factors } & \multicolumn{10}{|l|}{ Percentiles } \\
\hline & 0.05 & 0.15 & 0.25 & 0.35 & 0.45 & 0.55 & 0.65 & 0.75 & 0.85 & 0.95 \\
\hline \multirow[t]{2}{*}{ Constant } & 0.879 & 9.246 & 5.892 & 2.208 & 5.293 & 8.165 & 4.873 & 7.216 & 6.928 & 12.269 \\
\hline & $(0.065)$ & $(0.787)$ & $(0.725)$ & $(0.219)$ & $(0.520)$ & $(0.954)$ & $(0.549)$ & $(0.773)$ & $(0.761)$ & $(0.970)$ \\
\hline \multirow[t]{2}{*}{ TGF- $\beta 1$} & 246.281 & 394.203 & 481.854 & 508.789 & 575.917 & 593.743 & 629.329 & 637.585 & 624.232 & 838.401 \\
\hline & $\left(4.088^{\star \star}\right)$ & $(7.519 * \star)$ & $(13.296 * \star)$ & $\left(11.315^{\star \star}\right)$ & $(12.679 \star \star)$ & $\left(15.561^{\star \star}\right)$ & $\left(15.912^{\star \star}\right)$ & $\left(15.305^{\star \star}\right)$ & $\left(15.366^{\star \star}\right)$ & $(14.859 * \star)$ \\
\hline \multirow[t]{2}{*}{ Erk1/2 } & 120.037 & 17.122 & 37.736 & 35.942 & 5.311 & 8.878 & 7.135 & -19.103 & 10.072 & -28.314 \\
\hline & $(1.417)$ & $(0.232)$ & $(0.740)$ & $(0.568)$ & $(0.083)$ & $(0.165)$ & $(0.128)$ & $(-0.326)$ & $(0.176)$ & $(-0.357)$ \\
\hline \multirow[t]{2}{*}{ Smad $2 / 3$} & - & -16.223 & -66.575 & 2.282 & 35.236 & 22.914 & 56.750 & 98.069 & 92.868 & 9.671 \\
\hline & $74.443(1.113)$ & $(-0.223)$ & $(-1.322)$ & $(0.037)$ & $(0.558)$ & $(0.432)$ & $(1.033)$ & $(1.940)$ & (1.859) & $(0.123)$ \\
\hline \multirow[t]{2}{*}{ AKT } & 76.114 & 23.651 & -4.522 & -37.059 & -33.669 & -47.726 & -45.340 & -46.166 & 1.183 & 6.457 \\
\hline & (1.115) & $(0.364)$ & $(-0.101)$ & $(-0.665)$ & $(-0.598)$ & $(-1.009)$ & $(-0.924)$ & $(-0.893)$ & $(0.023)$ & $(0.092)$ \\
\hline \multirow[t]{2}{*}{ PI3K } & -59.305 & -61.242 & -57.044 & -26.049 & -34.215 & -11.215 & 16.930 & 9.701 & -4.563 & 23.487 \\
\hline & $(-0.800)$ & $(-0.950)$ & $(-1.280)$ & $(-0.471)$ & $(-0.613)$ & $(-0.239)$ & $(0.348)$ & $(0.189)$ & $(-0.091)$ & $(0.338)$ \\
\hline \multirow[t]{2}{*}{ MAPK } & -69.315 & 4.674 & -17.941 & -20.672 & 2.370 & 37.668 & 45.589 & 22.639 & -44.900 & -2.834 \\
\hline & $(-1.103)$ & $(0.086)$ & $(-0.475)$ & $(-0.441)$ & $(0.050)$ & $(0.947)$ & (1.106) & $(0.521)$ & $(-1.060)$ & $(-0.048)$ \\
\hline \multirow[t]{2}{*}{ JNK2 } & 34.819 & -3.160 & 19.572 & 18.803 & -20.441 & -72.192 & -65.744 & -94.286 & -88.809 & -130.496 \\
\hline & $(0.475)$ & $(-0.050)$ & $(0.444)$ & $(0.344)$ & $(-0.370)$ & $(-1.556)$ & $(-1.299)$ & $(-1.861)$ & $(-1.850)$ & $(-1.902)$ \\
\hline
\end{tabular}

Note: the values in parentheses were t value, ${ }^{*} P \otimes 0.05 \rrbracket \star \star P \otimes 0.01$

Table 6 Percentile regression analysis results of Emean and the expression levels of TGF- $\beta$ 1, Smad2/3, Erk1/2, p38 MAPK, JNK2, PI3K and AKT 


\begin{tabular}{|c|c|c|c|c|c|c|c|c|c|c|}
\hline \multirow[t]{2}{*}{ Factors } & \multicolumn{10}{|l|}{ Percentiles } \\
\hline & 0.05 & 0.15 & 0.25 & 0.35 & 0.45 & 0.55 & 0.65 & 0.75 & 0.85 & 0.95 \\
\hline \multirow[t]{2}{*}{ Constant } & 2.515 & 5.153 & 5.302 & 3.906 & 5.219 & 7.044 & 8.812 & 12.887 & 19.159 & 52.857 \\
\hline & $(2.764 * \star)$ & $(0.614)$ & $(0.607)$ & $(0.535)$ & $(0.937)$ & (1.129) & (1.174) & (1.893) & $\left(2.447^{\star}\right)$ & $\left(3.331^{\star \star}\right)$ \\
\hline \multirow[t]{2}{*}{ TGF- $\beta 1$} & 165.740 & 272.166 & 275.848 & 306.187 & 311.012 & 330.379 & 331.917 & 348.870 & 396.475 & 283.164 \\
\hline & $\left(40.847^{\star \star}\right)$ & $\left(7.273^{\star \star}\right)$ & $\left(7.078^{\star \star}\right)$ & $(9.404 \star *)$ & $\left(12.523^{\star \star}\right)$ & $(11.878 \star \star)$ & $\left(9.913^{\star \star}\right)$ & $\left(11.493^{\star *}\right)$ & $\left(11.353^{\star *}\right)$ & $\left(4.001^{\star *}\right)$ \\
\hline \multirow[t]{2}{*}{ Erk1/2 } & 9.134 & 27.242 & 5.337 & -19.645 & -14.899 & -26.436 & -62.152 & -89.939 & -70.397 & -137.854 \\
\hline & (1.869) & $(0.518)$ & $(0.097)$ & $(-0.429)$ & $(-0.427)$ & $(-0.676)$ & $(-1.320)$ & $\left(-2.107^{\star}\right)$ & $(-1.434)$ & $(-1.385)$ \\
\hline \multirow[t]{2}{*}{ Smad2/3 } & -10.401 & -29.460 & 28.310 & 59.515 & 48.011 & 74.255 & 34.924 & 149.744 & 87.728 & 167.575 \\
\hline & $(-1.948)$ & $(-0.590)$ & $(0.523)$ & $(1.316)$ & (1.391) & (1.921) & $(0.900)$ & $(3.550 * \star)$ & (1.808) & (1.738) \\
\hline \multirow[t]{2}{*}{ AKT } & 6.943 & 58.972 & -13.985 & -40.210 & 4.966 & 13.972 & -5.790 & -41.723 & -20.310 & -117.021 \\
\hline & (1.198) & (1.271) & $(-0.289)$ & $(-0.996)$ & $(0.161)$ & $(0.405)$ & $(-1.139)$ & $(-1.108)$ & $(-0.469)$ & $(-1.333)$ \\
\hline \multirow[t]{2}{*}{ PI3K } & -9.712 & -15.839 & -26.241 & 2.051 & -16.296 & -22.552 & -35.817 & -50.265 & -63.175 & -176.770 \\
\hline & $(-1.911)$ & $(-0.344)$ & $(-0.548)$ & $(0.051)$ & $(-0.534)$ & $(-0.659)$ & $(-0.870)$ & $(-1.347)$ & $(-1.471)$ & $(-1.761)$ \\
\hline \multirow[t]{2}{*}{ P38 MAPK } & -8.844 & -2.021 & 10.735 & -18.712 & -6.704 & -6.008 & 9.940 & 43.607 & 85.537 & 191.916 \\
\hline & $(-1.818)$ & $(-0.052)$ & $(0.264)$ & $(-0.551)$ & $(-0.259)$ & $(-0.207)$ & $(0.285)$ & (1.378) & (2.349) & $(1.836)$ \\
\hline \multirow[t]{2}{*}{ JNK2 } & 9.514 & -30.758 & -15.982 & 1.976 & -9.354 & -22.872 & 8.012 & 33.942 & -13.712 & 28.135 \\
\hline & (1.901) & $(-0.676)$ & $(-0.337)$ & $(0.050)$ & $(-0.310)$ & $(-0.676)$ & (0.197) & $(0.920)$ & $(-0.323)$ & $(0.327)$ \\
\hline
\end{tabular}

Note: the values in parentheses were t value, ${ }^{*} P \otimes 0.05 \rrbracket \star \star P ख 0.01$

Table 7 Percentile regression analysis results of Esd and the expression levels of TGF- $\beta$ 1, Smad2/3, Erk1/2, p38 MAPK, JNK2, PI3K and AKT

\begin{tabular}{|c|c|c|c|c|c|c|c|c|c|c|}
\hline \multirow[t]{2}{*}{ Factors } & \multicolumn{10}{|c|}{ Percentiles } \\
\hline & 0.05 & 0.15 & 0.25 & 0.35 & 0.45 & 0.55 & 0.65 & 0.75 & 0.85 & 0.95 \\
\hline \multirow[t]{2}{*}{ Constant } & 0.527 & -0.714 & 0.367 & -0.120 & -2.526 & -2.043 & -1.405 & -2.446 & -2.194 & -2.805 \\
\hline & $(0.474)$ & $(-0.311)$ & $(0.156)$ & $(-0.049)$ & $(-0.757)$ & $(-0.624)$ & $(-0.423)$ & $(-0.703)$ & $(-0.503)$ & $(-0.042)$ \\
\hline TGF- $\beta 1$ & 22.480 & 70.439 & 63.092 & 75.920 & 109.328 & 113.801 & 112.599 & 104.303 & 132.677 & 117.040 \\
\hline Erk1/2 & (1.758) & $(-0.891)$ & $(-0.653)$ & $(-0.671)$ & $(-0.137)$ & $(-0.498)$ & $(-0.334)$ & $(-0.191)$ & $(0.184)$ & $(0.407)$ \\
\hline \multirow[t]{2}{*}{ Smad2/3 } & -10.225 & -25.332 & -4.195 & 0.339 & 1.619 & 7.046 & 19.713 & 31.167 & 12.837 & 81.503 \\
\hline & $(-1.492)$ & $(-1.886)$ & $(-0.306)$ & $(0.023)$ & $(0.083)$ & $(0.368)$ & (1.014) & $(1.532)$ & $(0.503)$ & (1.912) \\
\hline PI3K & $(-1.163)$ & $(0.585)$ & $(-0.051)$ & $(0.263)$ & $(0.671)$ & (1.067) & (1.033) & (1.172) & $(0.661)$ & $(0.319)$ \\
\hline \multirow[t]{2}{*}{ P38 MAPK } & 5.410 & 13.940 & 10.201 & 11.205 & 10.597 & 11.347 & 12.809 & 1.537 & -18.073 & -49.386 \\
\hline & (1.138) & $(1.374)$ & $(0.984)$ & (1.024) & (0.719) & $(0.785)$ & $(0.872)$ & $(0.100)$ & $(-0.938)$ & $(-1.073)$ \\
\hline \multirow[t]{2}{*}{ JNK2 } & -11.226 & 7.915 & 5.724 & -2.051 & -12.575 & -15.636 & -24.628 & -18.915 & 9.965 & 22.565 \\
\hline & $(1.490)$ & $(0.673)$ & $(0.477)$ & $(-0.162)$ & $(-0.736)$ & $(-0.934)$ & $(-1.447)$ & $(-1.062)$ & $(0.446)$ & $(0.472)$ \\
\hline
\end{tabular}

Note: the values in parentheses were t value, ${ }^{*} P \otimes 0.05 \rrbracket \star \star P \otimes 0.01$ 


\begin{tabular}{|c|c|c|c|c|c|c|c|c|c|c|}
\hline \multirow[t]{2}{*}{ Factors } & \multicolumn{10}{|c|}{ Percentiles } \\
\hline & 0.05 & 0.15 & 0.25 & 0.35 & 0.45 & 0.55 & 0.65 & 0.75 & 0.85 & 0.95 \\
\hline \multirow[t]{2}{*}{ Constant } & -0.058 & -0.586 & 0.045 & 0.087 & 0.319 & 0.695 & 0.226 & 0.080 & -0.119 & 4.236 \\
\hline & $(-0.079)$ & $(-0.946)$ & $(0.077)$ & $(0.182)$ & $(0.687)$ & $(0.980)$ & $(0.284)$ & $(0.136)$ & $(-0.035)$ & $(0.441)$ \\
\hline \multirow[t]{2}{*}{ TGF- $\beta 1$} & 13.933 & 6.751 & 11.378 & 14.082 & 15.654 & 14.928 & 15.123 & 18.126 & 19.985 & 110.466 \\
\hline & $\left(4.601^{\star \star}\right)$ & $\left(2.509^{\star}\right)$ & $(4.419 * \star)$ & $(6.820 * \star)$ & $\left(7.768^{\star \star}\right)$ & $\left(4.840^{\star \star}\right)$ & $\left(4.366^{\star \star}\right)$ & $\left(7.125^{\star \star}\right)$ & $(7.339 * *)$ & $\left(7.731^{* \star}\right)$ \\
\hline \multirow[t]{2}{*}{ Erk1/2 } & 2.771 & 6.286 & 0.249 & -0.499 & -3.591 & -3.766 & -3.841 & -0.037 & 0.913 & -39.144 \\
\hline & $(0.608)$ & (1.648) & $(0.068)$ & $(-0.170)$ & $(-1.257)$ & $(-0.861)$ & $(-0.782)$ & $(-0.01)$ & $(0.043)$ & $(-0.662)$ \\
\hline \multirow[t]{2}{*}{ Smad2/3 } & -6.359 & -5.757 & -4.420 & -3.594 & -6.242 & -6.249 & -2.435 & -4.113 & -5.014 & 44.481 \\
\hline & $(-1.417)$ & $(-1.533)$ & $(-1.230)$ & $(-1.247)$ & $\left(-2.219^{\star}\right)$ & $(-1.451)$ & $(-0.504)$ & $(-1.158)$ & $(-0.241)$ & $(0.764)$ \\
\hline \multirow[t]{2}{*}{ AKT } & 5.978 & 3.844 & 1.196 & 0.376 & 2.971 & 3.361 & 3.160 & 2.215 & 3.831 & -15.238 \\
\hline & $(1.500)$ & (1.152) & $(0.375)$ & $(0.147)$ & $(1.189)$ & $(0.878)$ & $(0.736)$ & $(0.702)$ & $(0.207)$ & $(-0.295)$ \\
\hline \multirow[t]{2}{*}{ PI3K } & -1.496 & -0.647 & 2.862 & 3.808 & 3.338 & 3.905 & 5.633 & 5.043 & 4.127 & -13.009 \\
\hline & $(-0.378)$ & $(-1.196)$ & $(0.904)$ & $(1.500)$ & $(1.234)$ & $(1.209)$ & $(1.322)$ & $(1.612)$ & $(0.225)$ & $(-0.254)$ \\
\hline P38 & -2.112 & 0.385 & -1.337 & -1.521 & -2.104 & -0.774 & -2.010 & -0.933 & -2.056 & 5.076 \\
\hline MAPK & $(-0.630)$ & $(0.137)$ & $(-0.498)$ & $(-0.706)$ & $(-1.001)$ & $(-0.241)$ & $(-0.557)$ & $(-0.352)$ & $(-0.132)$ & $(0.117)$ \\
\hline \multirow[t]{2}{*}{ JNK2 } & 5.940 & 2.384 & 1.748 & 0.377 & 1.763 & 2.336 & 4.779 & 3.031 & 5.463 & 26.230 \\
\hline & $(1,503)$ & $(0.721)$ & $(0.552)$ & $(0.149)$ & $(0.712)$ & $(0.616)$ & (1.122) & (0.969) & $(0.298)$ & $(0.511)$ \\
\hline
\end{tabular}

Note: the values in parentheses were t value, ${ }^{*} P \Downarrow 0.05 \llbracket \star * P \Downarrow 0.01$

Table 9 The results of logistic regression analysis for determining the presence or absence of "stiff rim sign"

\begin{tabular}{|lllllll|}
\hline Factors & B & S.E. & Wald & $\boldsymbol{P}$ & OR & OR 95\%Cl \\
\hline TGF- $\beta 1 *$ & 17.049 & 5.005 & 11.602 & 0.001 & 25372088.366 & $1392.462-462305423321.366$ \\
\hline Constant * & -5.977 & 1.501 & 15.851 & 0.000 & 0.003 & - \\
\hline
\end{tabular}

\section{Figures}

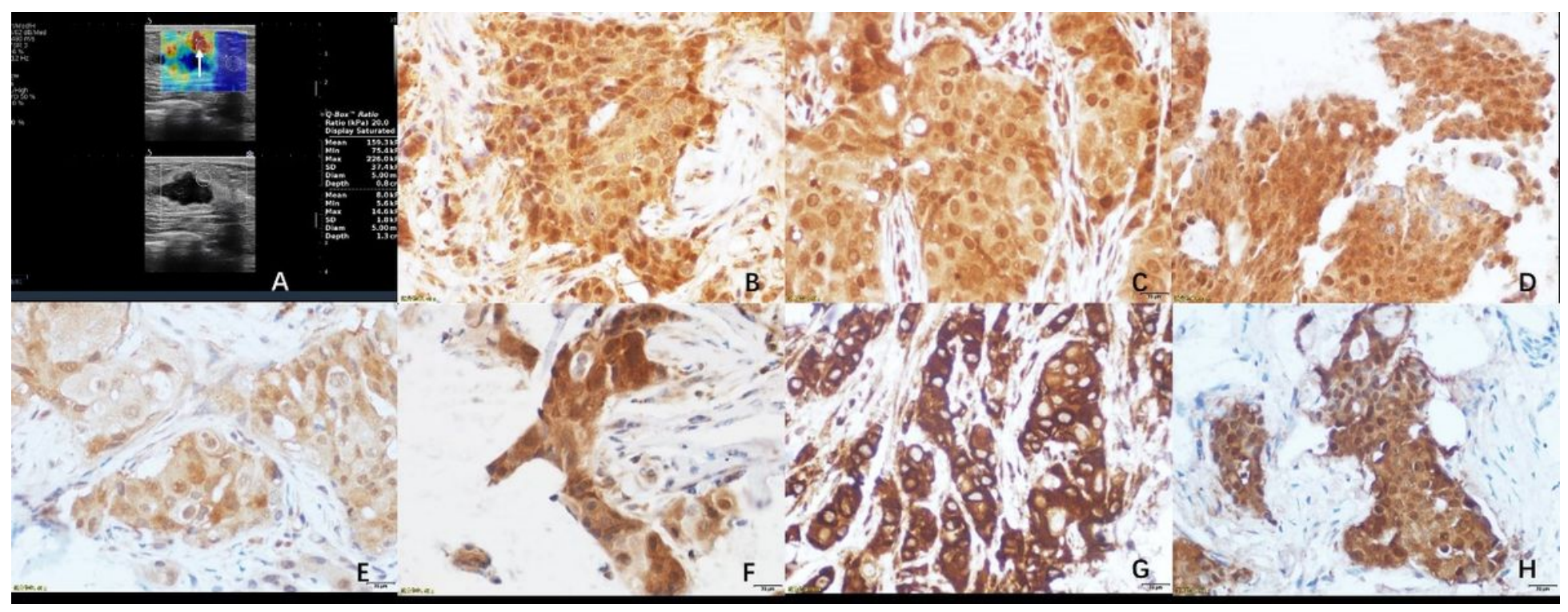

Figure 1

SWE and immunohistochemical images of invasive breast cancer in a 38-year-old woman. A: SWE showed that the Emax was $226.0 \mathrm{kPa}$, the Emean was $159.3 \mathrm{kPa}$, the Esd was $37.4 \mathrm{kPa}$, and the Eratio was 20.0, and the "stiff rim sign" (the white arrow) can be seen; B H: Immunohistochemical staining 
showed that the expression of TGF- $\beta 1$, Smad2/3, Erk1/2, p38 MAPK, JNK2, PI3K and AKT was strong or moderate positive, and the average optical density was $0.349,0.342,0.355,0.172,0.296,0.373,0.324$, respectively $(\times 400)$.

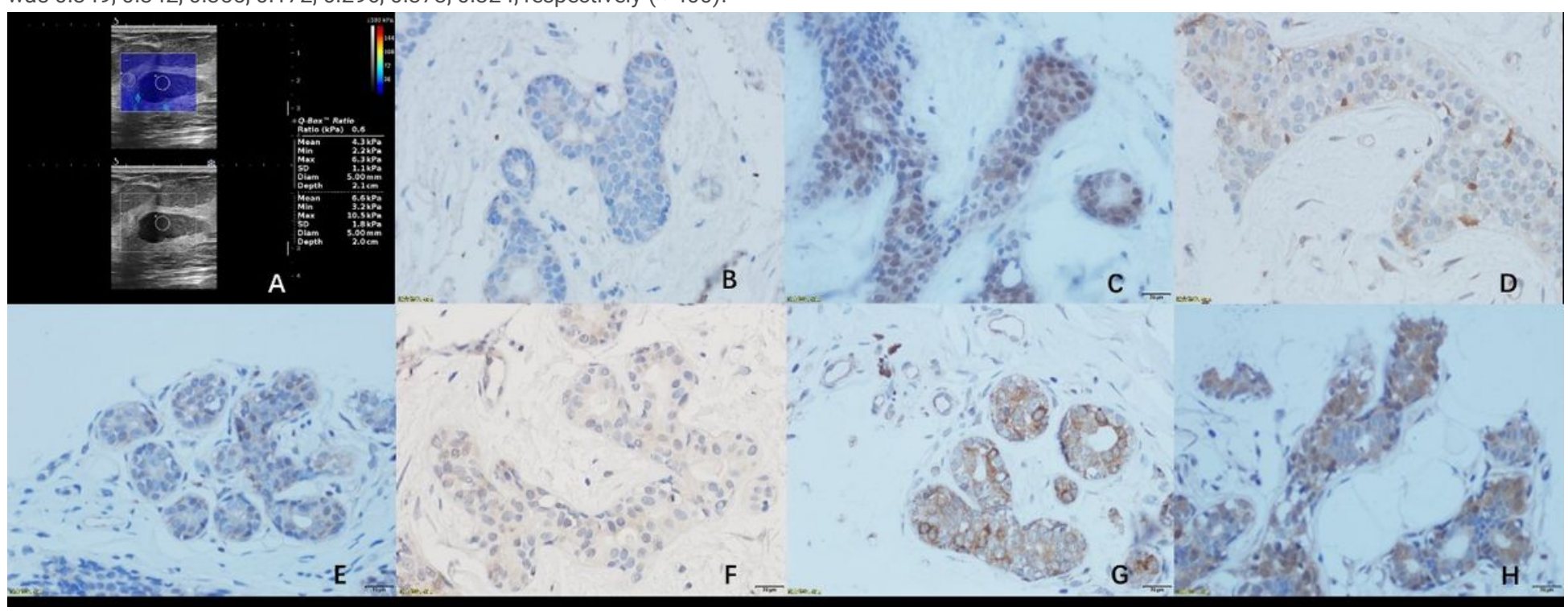

Figure 2

SWE and immunohistochemical images of breast fibroadenoma in a 36-year-old woman. A: SWE showed that the Emax was $6.3 \mathrm{kPa}$, the Emean was 4.3 $\mathrm{kPa}$, the Esd was $1.1 \mathrm{kPa}$, and the Eratio was $0.6 ; \mathrm{B} \sim \mathrm{H}$ : Immunohistochemical staining showed that the expression of TGF- $\beta 1$, Smad2/3, Erk1/2, p38 MAPK, JNK2, PI3K and AKT was weak positive, and the average optical density was $0.012,0.078,0.032,0.022,0.050,0.090,0.099$, respectively $(\times 400)$.

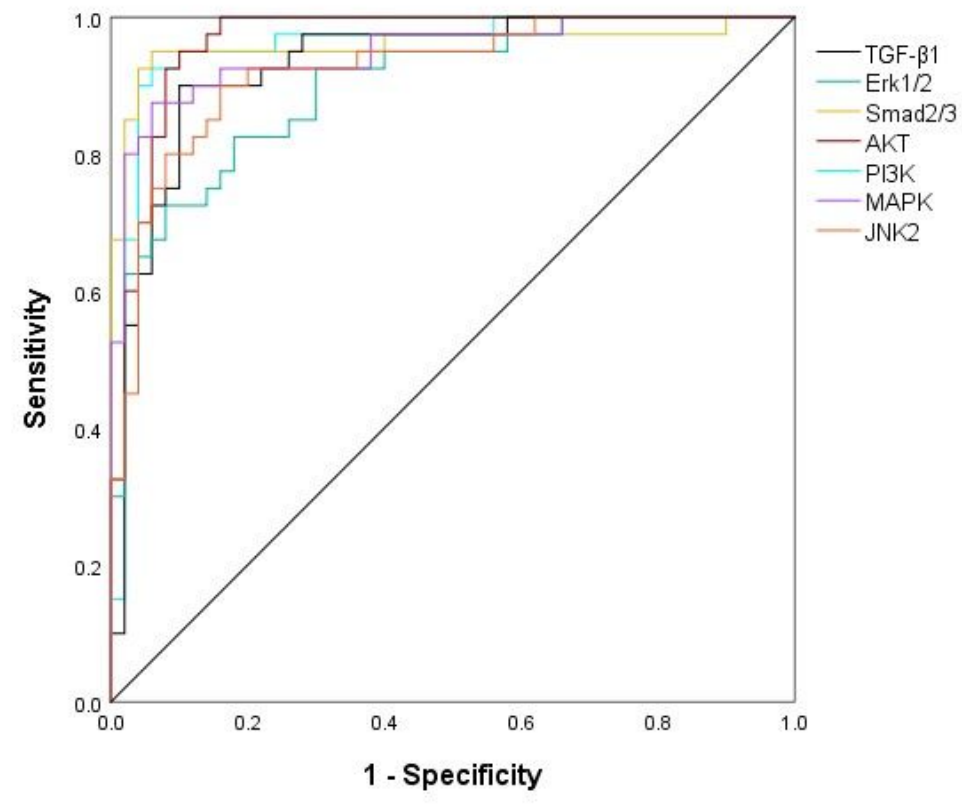

Figure 3

ROC curves of TGF- $\beta 1$, Smad2/3, Erk1/2, p38 MAPK, JNK2, PI3K and AKT expression levels in breast lesions for differential diagnosis of benign and malignant breast lesions. 


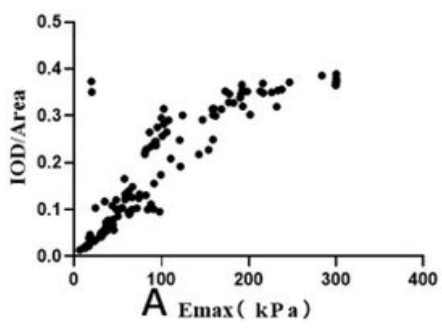

TGF- $\beta 1$

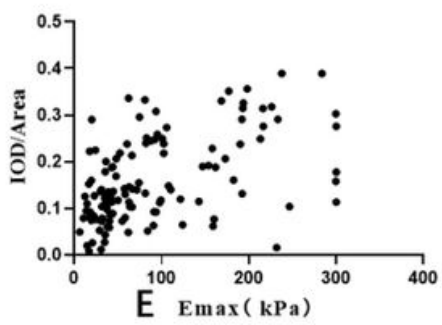

JNK2

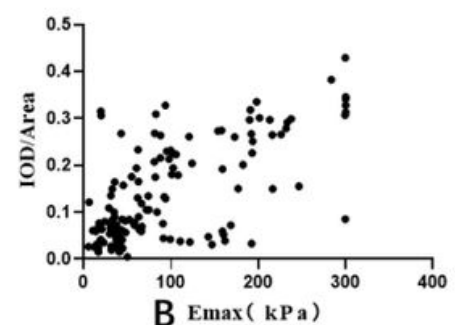

Smad2/3

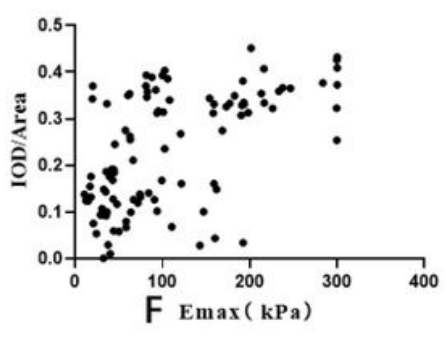

PI3K

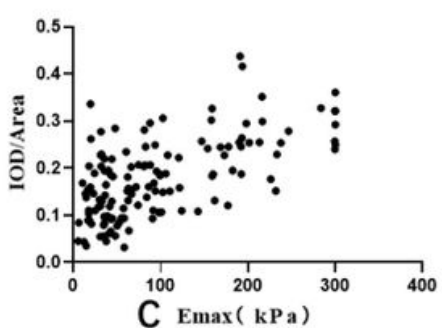

Erk1/2

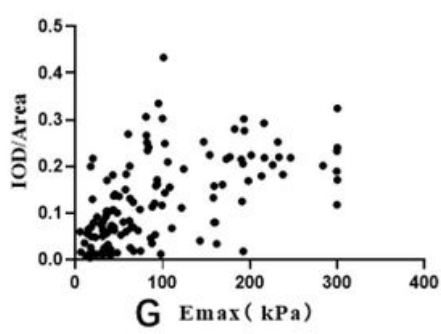

AKT

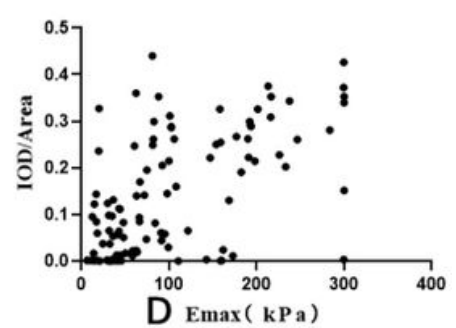

p38 MAPK

Figure 4

Correlations of TGF- $\beta 1$, Smad2/3, Erk1/2, p38 MAPK, JNK2, PI3K and AKT expression with Emax.

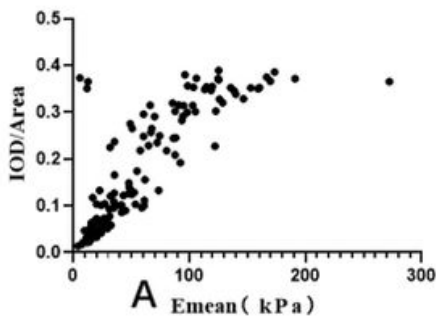

TGF- $\beta 1$

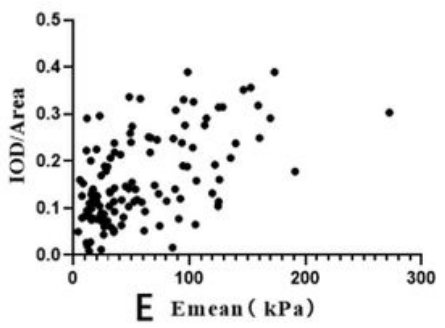

JNK2

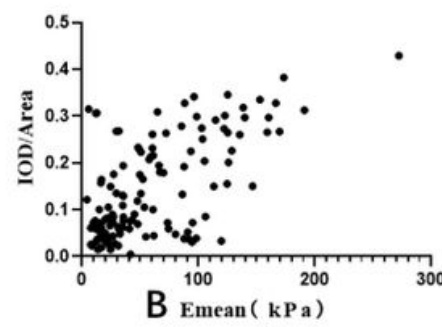

Smad2/3

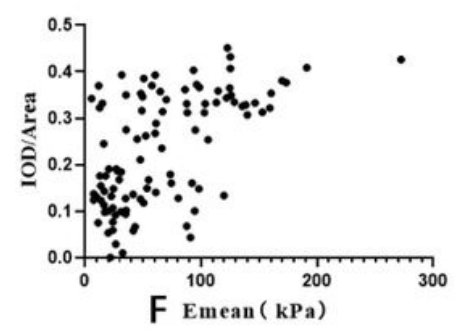

$\mathrm{PI} 3 \mathrm{~K}$

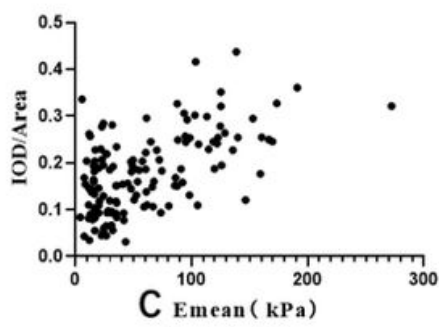

Erk1/2

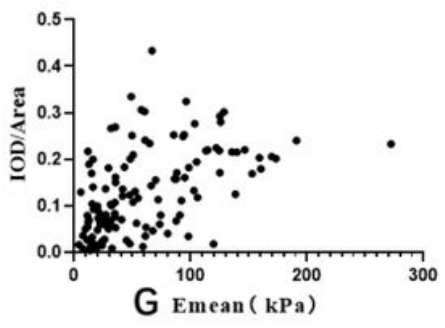

AKT

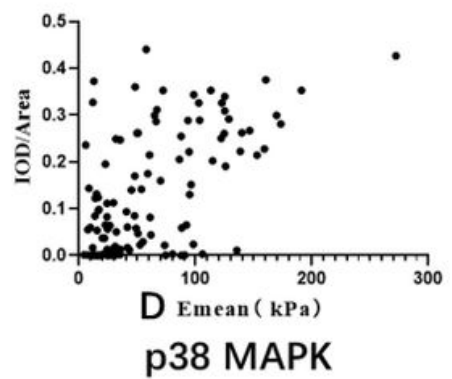

Figure 5

Correlations of TGF- $\beta 1$, Smad2/3, Erk1/2, p38 MAPK, JNK2, PI3K and AKT expression with Emean. 


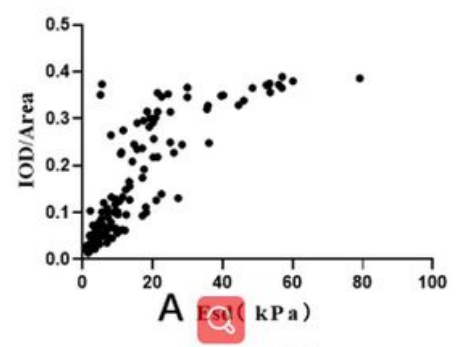

TGF- $\beta 1$

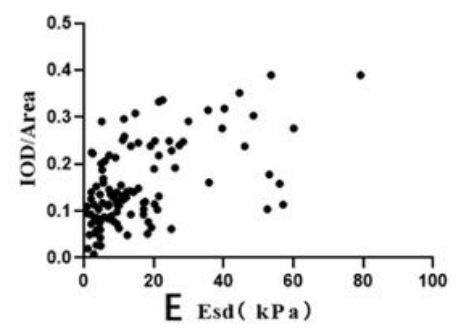

JNK2

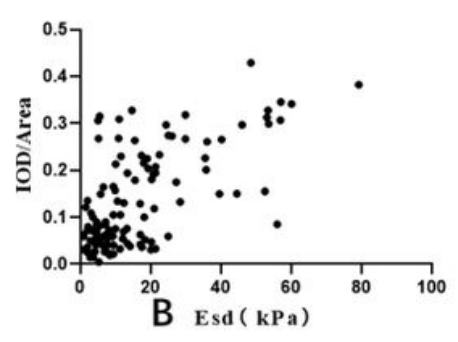

Smad2/3

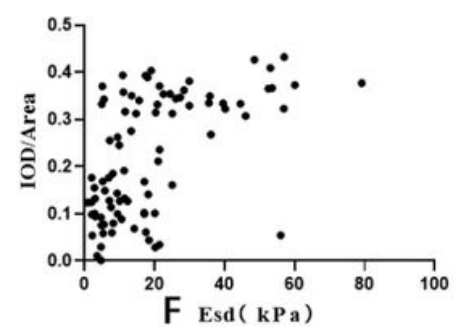

PI3K

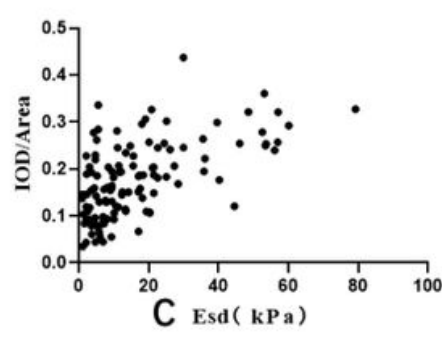

Erk1/2

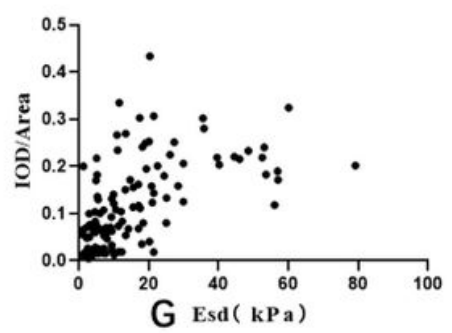

AKT

Figure 6

Correlations of TGF- $\beta 1$, Smad2/3, Erk1/2, p38 MAPK, JNK2, PI3K and AKT expression with Esd.

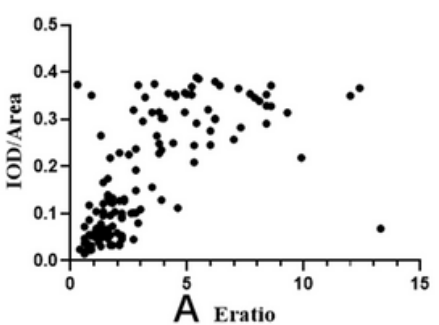

TGF- $\beta 1$

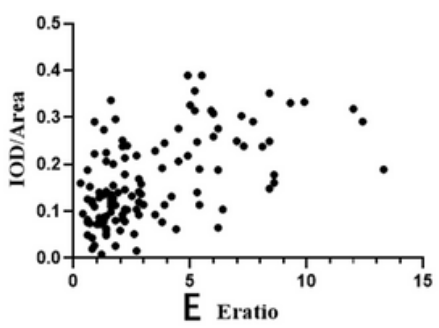

JNK2

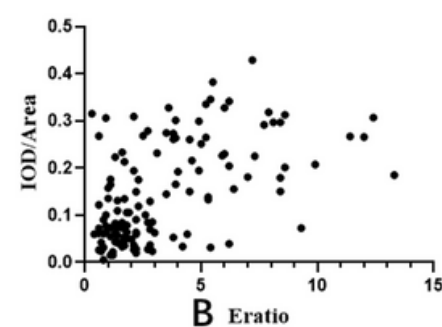

Smad2/3

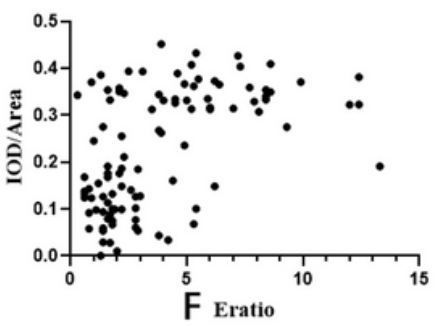

PI3K

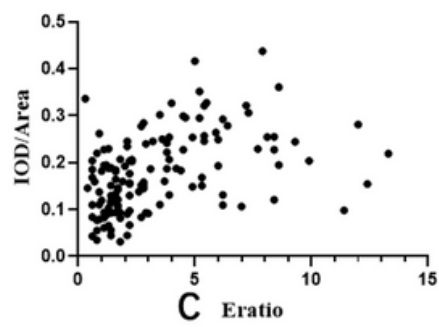

Erk1/2

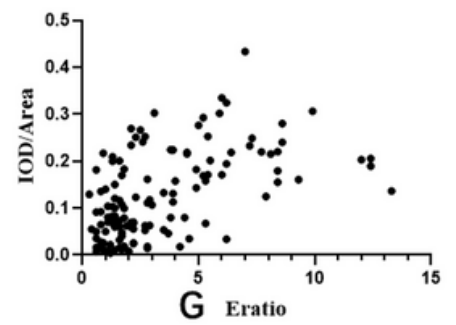

AKT

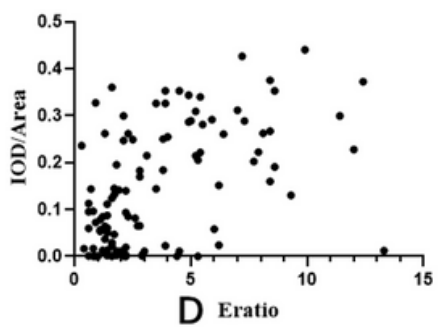

p38 MAPK

Figure 7

Correlations of TGF- $\beta 1$, Smad2/3, Erk1/2, p38 MAPK, JNK2, PI3K and AKT expression with Eratio. 


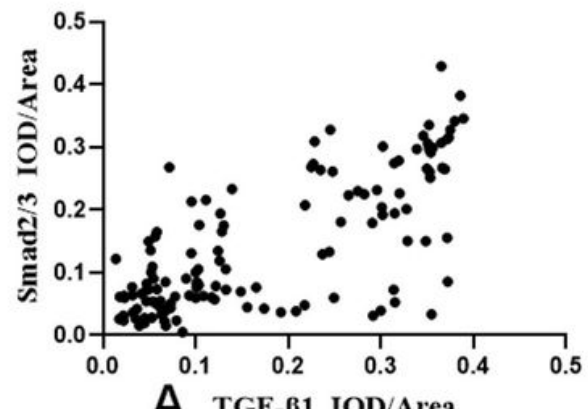

A TGF- $\beta 1$ IOD/Area

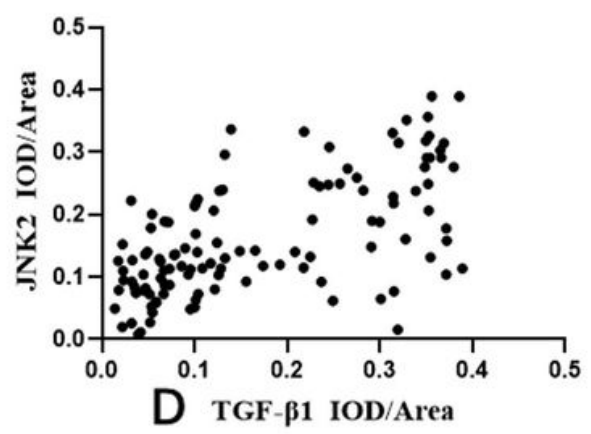

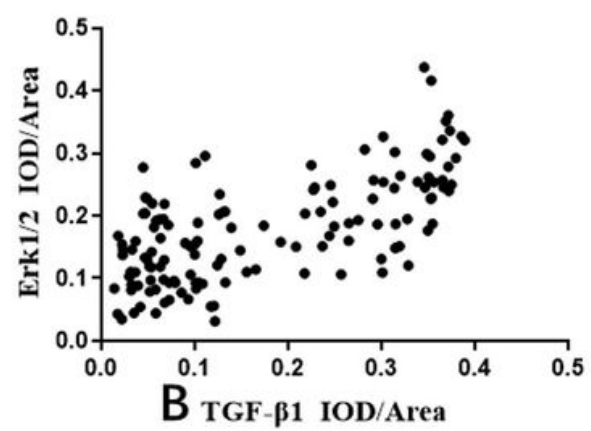

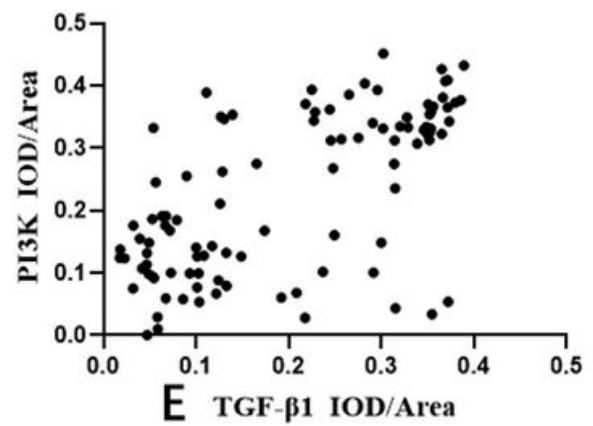

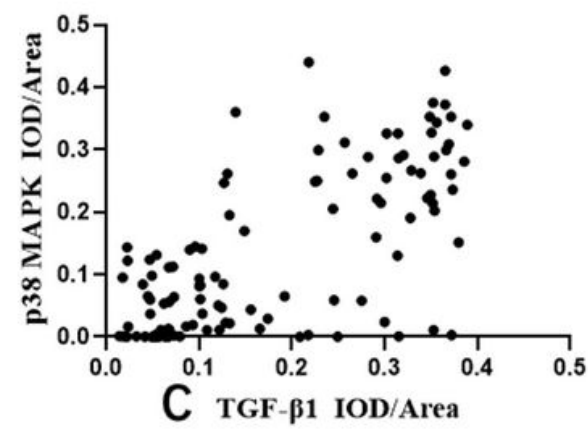

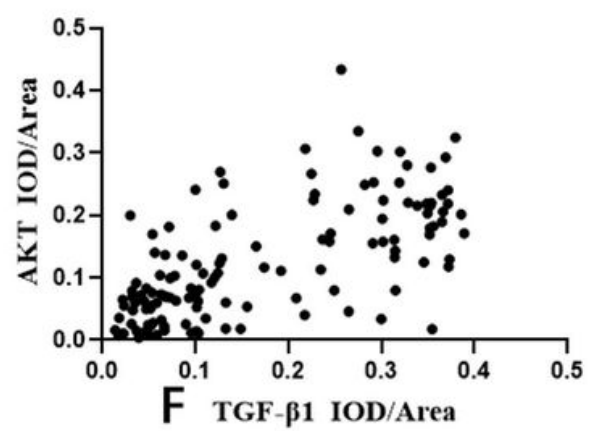

Figure 8

Correlations of Smad2/3, Erk1/2, p38 MAPK, JNK2, PI3K and AKT expression with TGF- $\beta 1$.

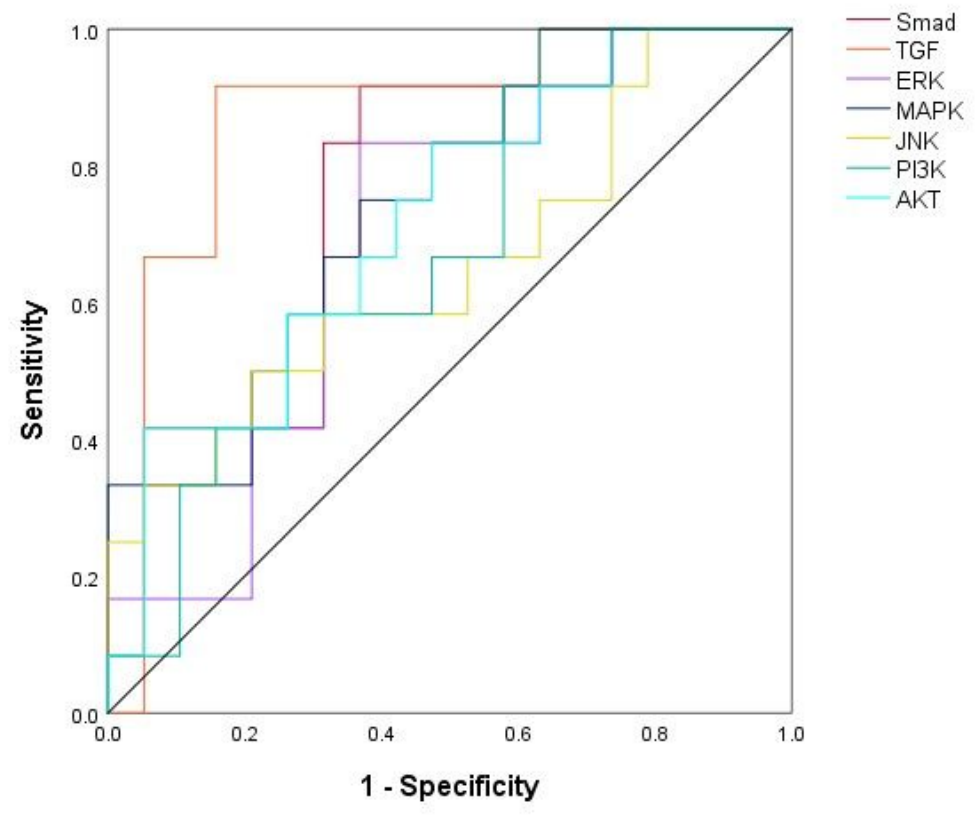

Figure 9

ROC curves of TGF- $\beta 1$, Smad2/3, Erk1/2, p38 MAPK, JNK2, PI3K and AKT expression levels in malignant breast lesions for differential diagnosis of malignant breast lesions with and without axillary lymph node metastasis 